\title{
Bioavailability of a dexlansoprazole delayed-release orally disintegrating tablet: effects of food and mode of administration
}

This article was published in the following Dove Press journal:

Clinical and Experimental Gastroenterology

17 February 2017

Number of times this article has been viewed

\author{
Michael Kukulka \\ Sai Nudurupati \\ Maria Claudia Perez \\ Takeda Development Center \\ Americas, Inc., Deerfield, IL, USA
}

Correspondence: Michael Kukulka Takeda Development Center Americas, Inc., One Takeda Parkway, Deerfield, IL 600I5, USA

Tel +l 2245542205

Fax + I 2245547933

Email michael.kukulka@takeda.com
Background: Dexlansoprazole is a proton pump inhibitor (PPI) approved for use in dual delayed-release capsule and orally disintegrating tablet (ODT) formulations.

Aim: To assess effects of food, water, and route of administration on the bioavailability of dexlansoprazole 30-mg ODT.

Methods: Two separate open-label, phase 1, single-dose crossover studies were conducted in healthy adults. In study 1, pharmacokinetic parameters were analyzed in participants receiving dexlansoprazole ODT in a fed or fasted state with and without water. In study 2, the bioavailability of dexlansoprazole after administration via oral syringe or nasogastric (NG) tube, or after swallowing intact with water was compared to ODT administration in the fasted state, swallowed without water. Blood samples for determining dexlansoprazole plasma concentrations and pharmacokinetic parameter estimates were collected before and after dosing.

Results: Equivalent values for area under the plasma concentration-time curve (AUC) were observed in the fed and fasted states, but the maximum observed plasma concentration $\left(\mathrm{C}_{\max }\right)$ was $38 \%$ lower in the fed state; therefore, bioequivalence was not achieved. A water rinse following standard ODT administration decreased dexlansoprazole bioavailability, with lower $\mathrm{C}_{\max }$ and AUC values than when ODT was administered without a water rinse. Bioequivalence was demonstrated when comparing the alternative routes of administration, including via oral syringe or NG tube with standard ODT administration. Unlike with a water rinse, bioequivalence to standard ODT administration (i.e., without water) was demonstrated when swallowing the ODT intact with water. Rates of adverse events were comparable irrespective of administration route in the fasted state $(6.7 \%-9.3 \%)$ and were $12 \%$ higher in the fed state than in the fasted state.

Conclusion: The AUC from the dexlansoprazole ODT was equivalent when administered in the fed and fasted states. Equivalent systemic exposure to dexlansoprazole was achieved regardless of the administration route.

Keywords: dexlansoprazole, bioavailability, proton pump inhibitor, orally disintegrating tablet, food effects, mode of administration

\section{Introduction}

Gastroesophageal reflux disease (GERD) is a common digestive acid-related disorder, most notably associated with symptoms of heartburn and acid regurgitation with a prevalence of up to $20 \%$ in North American adults. ${ }^{1,2}$ Options for drug therapy include acid-suppressing agents, such as antacids, histamine 2-receptor antagonists, and proton pump inhibitors (PPIs). PPIs are the treatment of choice for GERD symptom relief and healing of esophageal erosions. ${ }^{1}$ 
Dexlansoprazole is a PPI that suppresses gastric acid secretion by inhibiting the hydrogen-potassium adenosine triphosphatase pump in the gastric parietal cell; the final step of acid production is blocked by the specific action on this gastric proton pump. ${ }^{3}$ Dexlansoprazole dual delayed-release capsules are indicated for the healing of erosive esophagitis (EE), maintenance of healed EE and relief of heartburn, and the treatment of heartburn associated with symptomatic nonerosive GERD in patients $\geq 12$ years of age. ${ }^{3}$ The pharmacokinetic, pharmacodynamic, efficacy, and safety profiles following administration of dexlansoprazole 30-, 60-, and 90-mg capsules have been studied extensively. ${ }^{4-8}$ With the dual delayed-release formulation, the initial release of dexlansoprazole occurs 1-2 hours after dosing followed by a second release $4-5$ hours after dosing, allowing 24-hour control of intragastric acidity. ${ }^{8}$

The capsule and tablet formulations of most PPIs are intended to be swallowed, and thus, are not ideal for patients with difficulty swallowing. Difficulty swallowing is often present in patients who suffer from neurologic or muscular disorders, such as post-polio syndrome, multiple sclerosis, muscular dystrophy, Parkinson's disease, Alzheimer's disease, myasthenia gravis, scleroderma, and eosinophilic esophagitis, and other disorders that might restrict movement of the esophagus. ${ }^{9-13}$ Although epidemiologic data regarding reflux symptoms in neuromuscular disorders are scarce, GERD has a high prevalence $(26.5 \%)$ in a group of patients with Parkinson's disease and has also been associated with dysphagia in a general population study. ${ }^{14,15}$ In a populationbased survey of 7640 patients, GERD was the most common diagnosis among those who reported difficulty swallowing. ${ }^{16}$ Furthermore, in patients with severe dysphasia, especially the elderly with inadequate food intake and malnutrition, short-term use of a nasogastric (NG) tube is indicated. ${ }^{17}$ Consequently, a 30-mg orally disintegrating tablet (ODT) formulation of dexlansoprazole was developed for dosing flexibility, providing an alternative option for patients unable or unwilling to swallow capsules. The bioequivalence between 30-mg formulations of dexlansoprazole ODT and capsule was demonstrated in a phase 1 crossover study. ${ }^{18}$ Dexlansoprazole 30-mg ODT has recently been approved in the USA in patients $\geq 12$ years of age for the treatment of heartburn associated with symptomatic nonerosive GERD, maintenance of healed EE, and relief of heartburn, the same indications for which the dexlansoprazole 30-mg capsule is approved. A 60-mg daily dose of the capsule is also approved for the healing of EE. ${ }^{3}$

Herein, we describe the results from two separate studies conducted in healthy adults that assessed the effects of food, water, and alternative routes of administration on the bioavailability of 30-mg dexlansoprazole ODT. Study 1 measured the bioavailability of dexlansoprazole ODT in the fed and fasted states and with and without water in the fasted state. Study 2 compared the bioavailability of dexlansoprazole ODT administration directly on the tongue without water vs administration via oral syringe or NG tube after the tablet was allowed to disintegrate in water or after swallowing the ODT intact with water.

\section{Materials and methods}

The effects of various dexlansoprazole ODT dosing regimens and multiple routes of administration on bioavailability were assessed in two phase 1, randomized, open-label, single-center, single-dose crossover studies conducted in healthy adults in the USA. Study 1 assessed the bioavailability of dexlansoprazole in the fed and fasted states and with and without consumption of water in the fasted state. Study 2 evaluated bioavailability after using different routes of delivering the dexlansoprazole ODT in fasting participants. Study 1 was conducted at the Covance Madison Clinical Research Unit in Madison, Wisconsin, from April to August 2012 and study 2 was conducted at Celerion in Neptune, NJ, USA from August to December 2012. Both studies were designed according to the Food and Drug Administration of the United States (FDA) Guidance for Industry: Bioavailability and Bioequivalence Studies for Orally Administered Drug Products - General Considerations. ${ }^{19}$ Study 1 was also performed with consideration to the FDA Guidance for Industry: Food-Effect Bioavailability and Fed Bioequivalence Studies. ${ }^{20}$ Trial protocols met the principles within the Declaration of Helsinki ${ }^{21}$ and the International Conference on Harmonisation (ICH) Harmonised Tripartite Guideline for Good Clinical Practice, ${ }^{22}$ and were approved by the Independent Investigational Review Boards at each site (Chesapeake Research Review, Inc., Columbia, Maryland, USA and Independent Investigational Review Board INC, Plantation, FL, USA). Trial registration was not required for either study at the time of conduct, as phase 1 drug trials are excluded from US Food and Drug Administration Amendments Act 801 registration requirements. ${ }^{23}$ All participants gave written informed consent before beginning the study.

\section{Study participants}

Eligible participants were healthy adults between the age of 18 and 55 years and weighed $\geq 50 \mathrm{~kg}$ with a body mass index $\geq 18$ and $\leq 30 \mathrm{~kg} / \mathrm{m}^{2}$. Participants with any clinically significant hematologic, neurologic, cardiovascular, pulmonary, hepatic, renal, metabolic, gastrointestinal, urological, immunologic, endocrine, or psychiatric disorder, or history of malignant disease were ineligible for enrollment. Participants 
were also considered ineligible if they had recently received agents that could alter hepatic or renal clearance, or contained nicotine, caffeine, xanthine, or grapefruit products, or if they had evidence of either drug or alcohol consumption. A known hypersensitivity to any component of dexlansoprazole ODT, dexlansoprazole capsules, or other PPIs, or prior use of dexlansoprazole, lansoprazole, or any investigational compound for any indication within 30 days before check-in (day -1 of the first treatment period) were grounds for study exclusion. In addition, both non-sterilized male participants and female participants of childbearing potential had to agree to routine contraception use for the duration of the study and for the 30 days after the last dose. If participants did not meet any of the entry criteria after randomization, they were removed at the discretion of the investigator and not replaced. Participants could also be discontinued because of adverse events.

\section{Treatment regimens}

Participants were randomized to one of three (study 1) or four (study 2) treatment sequences; each comprised three (study 1) or four (study 2) treatment periods (Tables S1 and S2). For each treatment period, participants were confined to the study site from the day before dose administration until all study procedures had been completed on day 2. A single dose of dexlansoprazole 30-mg ODT was administered on day 1 of each treatment period according to the dosing regimen dictated by the treatment sequence. Participants were discharged from the study site for a washout interval of at least 5 days between subsequent treatment periods. A follow-up phone call was made 5-10 days after the final dose of study drug to monitor for any ongoing or emergent adverse events.

\section{Reference regimen}

The reference regimen in both studies required administering dexlansoprazole ODT directly on the tongue without water. Participants were instructed to allow the tablet to disintegrate and to swallow the granules without chewing. Participants could drink water at any time outside of the 2-hour window ranging from 1 hour before and after receiving the drug. Participants receiving the reference regimen were to have fasted for $\geq 10$ hours before dosing and remained fasting for 4 hours postdose.

\section{Study I (effects of food and water) test regimens}

In this study, participants were randomized in a 1:1:1 ratio to three possible treatment sequences, each including a period where they received tests $1 \mathrm{~A}, 1 \mathrm{~B}$, or the reference regimen (Table S1). With test regimen 1A, the bioavailability of dexlansoprazole ODT when administered in the fed state without water was examined. Participants fasted overnight for $\geq 10$ hours and were served a high-fat breakfast 30 minutes before the scheduled dose. The tablet was then administered without water as in the reference regimen. In test regimen $1 \mathrm{~B}$, the bioavailability of dexlansoprazole ODT when administered with water was examined. A single dose of dexlansoprazole ODT was administered after a minimum 10-hour fast according to the reference regimen, but was then followed by consumption of $240 \mathrm{~mL}$ of water (the recommended volume of administration stated by the $F D A$ Guidance for Industry: Bioavailability and Bioequivalence Studies Submitted in NDAs or INDs-General Considerations $)^{19}$ after the tablet was disintegrated on the tongue and swallowed. All participants were limited to the standardized meals and snacks provided by the site. Breakfast was only served during the treatment period for test regimen $1 \mathrm{~A}$, and all groups received lunch and dinner.

\section{Study 2 (alternative routes of administration) test regimens}

In this study, participants were randomized in a 1:1:1:1 ratio to four possible treatment sequences, each including a treatment period for the tests $2 \mathrm{~A}, 2 \mathrm{~B}, 2 \mathrm{C}$, or reference regimen (Table $\mathrm{S} 2$ ). With test regimens $2 \mathrm{~A}$ and $2 \mathrm{~B}$, the bioavailability of dexlansoprazole ODT was examined when administered orally via syringe or an 8 French NG tube directly to the stomach, respectively. In both regimens, the intact tablet was placed into a syringe and allowed to disintegrate in 15-20 mL of water. After initial administration in each regimen, an additional 10 $\mathrm{mL}$ of water was used to rinse the dosing syringe. This rinse was performed twice, and the water used for the rinse was administered to participants after each rinse. With test regimen $2 \mathrm{C}$, a single dose of dexlansoprazole ODT was administered orally with direction to swallow the tablet intact with $240 \mathrm{~mL}$ of water.

\section{Evaluations}

In both studies, blood samples $(3 \mathrm{~mL})$ were collected from a peripheral vein at $\leq 30$ minutes before treatment and at 0.5 , $1,1.5,2,3,4,5,6,7,8,10,12,16$, and 24 hours after dose administration. Plasma concentrations of dexlansoprazole were measured by a proprietary validated liquid chromatography tandem mass spectrometry assay at PPD Development in Middleton, WI, USA. During assay validation, the accuracy (percent difference from theoretical concentrations) and precision (percent coefficient of variation) for dexlansoprazole quality control samples were determined to be $-3.83 \%$ to $1.07 \%$ and $2.45 \%$ to $4.56 \%$, respectively. The validated concentration range for dexlansoprazole was 2.00-2000 ng/mL; values below this range were set to zero 
for pharmacokinetic analysis. In addition, because dexlansoprazole is metabolized by the cytochrome P450 (CYP) 2C19 enzyme, increased plasma concentrations of dexlansoprazole may be observed in CYP2C19 poor metabolizers; therefore, a single blood sample was collected from all participants for the determination of CYP2C19 metabolizer status.

Primary endpoints for both studies included the maximum observed drug concentration in the plasma $\left(\mathrm{C}_{\max }\right)$ and the amount of systemic drug exposure, determined by the area under the plasma concentration-time curve (AUC). The AUC values presented were measured from time 0 extrapolated to infinity $\left(\mathrm{AUC}_{\infty}\right)$. The rate of absorption $\left(\mathrm{T}_{\max }\right)$, defined as the time to reach $\mathrm{C}_{\max }$, was a primary endpoint in study 1 and a secondary endpoint in study 2 . The apparent clearance after extravascular administration $(\mathrm{CL} / \mathrm{F})$, the terminal elimination half-life $\left(\mathrm{T}_{1 / 2}\right)$, and the apparent volume of distribution after extravascular administration $(\mathrm{Vz} / \mathrm{F})$ were also included as secondary endpoints in study 2 .

\section{Statistical analysis}

Within each study, individual pharmacokinetic parameters were generated using Phoenix WinNonlin Version 6.3 (Certara, Princeton, NJ, USA) and analyzed with SAS (Statistical Analysis System) Version 9.2 software (SAS Institute, Cary, NC, USA). Actual sampling times were used over scheduled sampling times in all pharmacokinetic parameter calculations. Values for $\mathrm{T}_{\max }$ and $\log$-transformed $\mathrm{C}_{\max }$ and AUC were analyzed using the analysis of variance model with sequence, period, and regimen as fixed effects and the study participant nested within sequence as a random effect. Pharmacokinetic parameters from participants who had data for the reference regimen and at least one of the test regimens were included in the statistical analyses.

Statistical comparisons evaluated the point estimate and $90 \%$ confidence intervals ( $\mathrm{CIs}$ ) for the $\mathrm{C}_{\max }$ and AUC central value ratios of the test and reference regimens. Bioequivalence between regimens was declared if the CIs fell within the range of $0.80-1.25 .^{20}$

A sample size of 72 (24 per treatment sequence) and 80 (20 per treatment sequence) participants was used in studies 1 and 2 , respectively. These sample sizes allowed for dropout rates of $\sim 8 \%$ (study 1 ) and $20 \%$ (study 2 ) and provided at least $88 \%$ probability of concluding equivalence on dexlansoprazole $\mathrm{C}_{\max }$ between 2 regimens if the true difference between dexlansoprazole $\mathrm{C}_{\max }$ central values from 2 regimens was not $>5 \%$. The power for concluding equivalence on dexlansoprazole AUCs between 2 regimens was expected to be $>95 \%$ for both studies.

Genetic variations between individuals, including CYP polymorphisms, could potentially affect bioavailability estimates. However, CYP2C19 genotype was not expected to affect the assessment of bioavailability because each participant received both treatment regimens, serving as his or her own control in the crossover study design employed. Consequently, no formal statistical analyses were conducted based on CYP2C19 genotype.

\section{Results}

\section{Study participants}

In total, 72 and 77 participants were randomized in studies 1 and 2, respectively (Tables S1 and S2). Participant demographics were comparable across treatment sequences within each study (Table 1).

\section{Pharmacokinetic parameter estimates of dexlansoprazole ODT administration with and without food or water}

Pharmacokinetic parameter estimates following dexlansoprazole ODT administration in the fed and fasted states with and without water are summarized for each regimen in Table 2. The absorption of dexlansoprazole ODT was slower in the fed state with a median $\mathrm{T}_{\max }$ of 6 vs 4 hours in the fasted state (Table 2). Furthermore, the mean $\mathrm{C}_{\max }$ was lower in the fed state $(445 \mathrm{ng} / \mathrm{mL})$ than in the fasted state $(688 \mathrm{ng} / \mathrm{mL}$; Table 2). The mean AUC, which measures systemic exposure, was similar between the fed and fasted states (Table 2); similar values for mean $\mathrm{T}_{1 / 2}, \mathrm{CL} / \mathrm{F}$, and $\mathrm{Vz} / \mathrm{F}$ between the two regimens

Table I Demographic and baseline characteristics

\begin{tabular}{|c|c|c|}
\hline Characteristic & Study I & Study 2 \\
\hline & $\begin{array}{l}\text { All } \\
\text { participants } \\
(\mathbf{N}=72)\end{array}$ & $\begin{array}{l}\text { All } \\
\text { participants } \\
(\mathbf{N}=\mathbf{7 7})\end{array}$ \\
\hline Age, years (mean $\pm S D)$ & $32.5 \pm 9.85$ & $38.0 \pm 9.80$ \\
\hline Sex, male (n, \%) & $37(5 \mid .4)$ & $63(81.8)$ \\
\hline Hispanic/Latino, yes (n, \%) & 0 & $23(29.9)$ \\
\hline \multicolumn{3}{|l|}{ Race $(n, \%)$} \\
\hline Asian & $2(2.8)$ & $2(2.6)$ \\
\hline Black/African American & $12(16.7)$ & $39(50.6)$ \\
\hline White & $54(75.0)$ & $32(4 \mid .6)$ \\
\hline Multiracial & $4(5.6)$ & $3(3.9)$ \\
\hline $\mathrm{BMI}, \mathrm{kg} / \mathrm{m}^{2}($ mean $\pm \mathrm{SD})$ & $24.62 \pm 2.94$ & $25.2 \pm 2.66$ \\
\hline \multicolumn{3}{|l|}{ Smoking classification (n, \%) } \\
\hline Never smoked & $62(86.1)$ & 71 (92.2) \\
\hline Current smoker & 0 & $\mathrm{I}(\mathrm{I} .3)$ \\
\hline Ex-smoker & $10(13.9)$ & $5(6.5)$ \\
\hline \multicolumn{3}{|l|}{ Alcohol classification (n, \%) } \\
\hline Never drunk & $14(19.4)$ & $77(100)$ \\
\hline Current drinker & $55(76.4)$ & 0 \\
\hline Ex-drinker & $3(4.2)$ & 0 \\
\hline Caffeine consumption, yes (n, \%) & $58(80.6)$ & $12(15.6)$ \\
\hline
\end{tabular}

Abbreviations: BMI, body mass index; SD, standard deviation. 
Table 2 Study I: pharmacokinetic parameter estimates after administration of dexlansoprazole ODT with or without food or water

\begin{tabular}{|c|c|c|c|c|c|c|}
\hline & $\mathbf{T}_{\max }(\mathbf{h})$ & $C_{\max }(\mathrm{ng} / \mathrm{mL})$ & $A_{\infty} C_{\infty}(\mathrm{ng} \mathrm{h} / \mathrm{mL})$ & $\mathbf{T}_{1 / 2}$ (h) & CL/F (L/h) & Vz/F (L) \\
\hline \multicolumn{7}{|c|}{ Test regimen IA: fed state, without water } \\
\hline Participants (n) & 66 & 66 & 65 & 65 & 65 & 65 \\
\hline Mean \pm SD & NR & $445 \pm 252$ & $2744 \pm 2554.8$ & $2.00 \pm 1.02$ & $17.45 \pm 11.33$ & $44.40 \pm 32.56$ \\
\hline Median (min, max) & $6.00(1.5,10.08)$ & $397(54,1450)$ & $1896(435,15558)$ & $\mathrm{I} .68(0.77,5.8 \mathrm{I})$ & $15.82(1.93,68.91)$ & $35.21(15.8 I,|7| .50)$ \\
\hline$\% \mathrm{CV}$ & NR & 57 & 93 & 51 & 65 & 73 \\
\hline \multicolumn{7}{|c|}{ Test regimen IB: fasted state, with water } \\
\hline Participants (n) & 64 & 64 & 64 & 64 & 64 & 64 \\
\hline Mean \pm SD & NR & $508 \pm 298$ & $2402 \pm 2251.3$ & $2.59 \pm 1.53$ & $20.58 \pm 13.54$ & $71.98 \pm 67.22$ \\
\hline Median (min, max) & $4.00(1.05,7.00)$ & $448(84,1580)$ & $1664(394,12,984)$ & $1.90(0.71,7.57)$ & $18.03(2.3 \mid, 76.20)$ & $48.90(12.83,424.98)$ \\
\hline$\% \mathrm{CV}$ & NR & 59 & 94 & 59 & 66 & 93 \\
\hline \multicolumn{7}{|c|}{ Reference regimen: fasted state, without water } \\
\hline Participants (n) & 67 & 67 & 67 & 67 & 67 & 67 \\
\hline Mean \pm SD & NR & $688 \pm 328$ & $2839 \pm 2437.7$ & $2.07 \pm 1.57$ & $16.01 \pm 9.66$ & $47.35 \pm 65.98$ \\
\hline Median (min, max) & $4.00(1.50,6.00)$ & $630(193,1690)$ & $2216(634,12,882)$ & I.5I $(0.70,8.53)$ & $13.54(2.33,47.30)$ & $29.29(12.26,424.26)$ \\
\hline$\% \mathrm{CV}$ & NR & 48 & 86 & 76 & 60 & 139 \\
\hline
\end{tabular}

Notes: Because of variability in the terminal phase of the plasma concentration-time curve, the terminal elimination rate constant could not be determined for some study participants, and therefore the PK parameters that use this constant in their calculations (i.e., $\mathrm{T}_{1 / 2}, \mathrm{AUC}, \mathrm{CL} / \mathrm{F}$, and $\mathrm{Vz} / \mathrm{F}$ ) could not be estimated.

Abbreviations: $A \cup C_{\infty}$, area under the plasma concentration-time curve from time 0 to infinity; CL/F, apparent clearance after extravascular administration; $C_{\text {max }}$ maximum observed plasma concentration; \%CV, percent coefficient of variation; max, maximum; min, minimum; NR, not reported; ODT, orally disintegrating tablet; $\mathrm{PK}$, pharmacokinetic; SD, standard deviation; $\mathrm{T}_{1 / 2}$, terminal elimination half-life; $\mathrm{T}_{\max }$, time to reach maximum observed plasma concentration; $\mathrm{Vz} / \mathrm{F}$, apparent volume of distribution after extravascular administration.

were also observed (Table 2). When statistically comparing ODT administration in fed and fasted states, the $90 \%$ CIs of dexlansoprazole AUC values (0.8776-1.0242) were contained within the predetermined range of bioequivalence - that is, within 0.80-1.25 (Table 3; Figure 1). The 90\% CI for $\mathrm{C}_{\max }$ did not meet bioequivalence criteria (0.5568-0.6908) and the point estimate suggests that the peak concentration was $\sim 38 \%$ lower in the fed state (Table 3; Figure 1).

When comparing dexlansoprazole ODT administration with and without water (test regimen $1 \mathrm{~B}$ and reference regimen, respectively) similar rates of absorption were observed with median $\mathrm{T}_{\max }$ of 4 hours each (Table 2). Participants receiving the ODT with water had a $26 \%$ lower mean $\mathrm{C}_{\max }$ than those receiving the reference regimen $(508 \mathrm{ng} / \mathrm{mL}$ vs $688 \mathrm{ng} / \mathrm{mL}$, respectively; Table 2). Mean AUC was also 15\% lower when administration of the ODT was followed with water (Table 2). The $90 \%$ CIs for both $\mathrm{C}_{\max }$ and AUC values were not in the prespecified range for bioequivalence (Table 3; Figure 1). Mean $\mathrm{T}_{1 / 2}$ values were similar between the two regimens (Table 2).

\section{Pharmacokinetic parameter estimates of dexlansoprazole after using alternative routes of administration}

Pharmacokinetic parameter estimates after using alternative routes of dexlansoprazole ODT administration were summarized for each regimen (Table 4). The absorption of dexlansoprazole was similar irrespective of the method of delivery, with all regimens reaching maximum plasma concentrations
Table 3 Study I: statistical comparisons of pharmacokinetic parameter estimates after administration of dexlansoprazole ODT with or without food or water

\begin{tabular}{|c|c|c|c|}
\hline \multirow[t]{2}{*}{ Parameters } & \multicolumn{2}{|c|}{ Participants (n) } & \multirow{2}{*}{$\begin{array}{l}\text { Relative bioavailability } \\
\text { point estimate }(90 \% \mathrm{CI})\end{array}$} \\
\hline & Test & Reference & \\
\hline \multicolumn{4}{|c|}{ Test regimen IA (fed state) vs reference regimen ${ }^{a}$} \\
\hline $\mathrm{C}_{\max }$ & 66 & 67 & $0.6202(0.5568-0.6908)$ \\
\hline $\mathrm{AUC}_{\infty}$ & 65 & 67 & $0.948 I(0.8776-1.0242)$ \\
\hline \multicolumn{4}{|c|}{ Test regimen IB (fasted state with water) vs reference regimen } \\
\hline $\mathrm{C}_{\max }$ & 64 & 67 & $0.7110(0.6375-0.7930)$ \\
\hline AUC & 64 & 67 & $0.8023(0.7423-0.8672)$ \\
\hline
\end{tabular}

Notes: Participants with PK parameter data for the reference regimen and one of the test regimens are included in the statistical analyses. ${ }^{2}$ Reference regimen: a single dose of dexlansoprazole 30-mg ODT was administered on the tongue without water after a minimum 10-hour fast. Participants were instructed to allow the tablet to disintegrate and to swallow the granules without chewing.

Abbreviations: $A \cup C_{\text {, }}$, area under the plasma concentration-time curve from time 0 to infinity; $\mathrm{Cl}$, confidence interval; $\mathrm{C}_{\text {max }}$, maximum observed plasma concentration; ODT, orally disintegrating tablet; PK, pharmacokinetic.

at 4 hours (Table 4). Similarly, mean $\mathrm{C}_{\max }$ and $\mathrm{AUC}$ values were consistent for all routes of administration, ranging from 744 to $786 \mathrm{ng} / \mathrm{mL}$ and from 3043 to $3340 \mathrm{ng} \cdot \mathrm{h} / \mathrm{mL}$, respectively (Table 4). No differences were observed for the secondary endpoints of $\mathrm{T}_{1 / 2}, \mathrm{CL} / \mathrm{F}$, and $\mathrm{Vz} / \mathrm{F}$ (Table 4). All point estimates of relative bioavailability for $\mathrm{C}_{\max }$ and $\mathrm{AUC}$ had $90 \%$ CIs that fell within the range for bioequivalence (0.80-1.25), indicating equivalent pharmacokinetic profiles between dexlansoprazole ODT administered via oral syringe, via an NG tube, or as an intact tablet swallowed with water and the reference regimen (i.e., administered intact on the tongue without water; Table 5; Figure 2). 


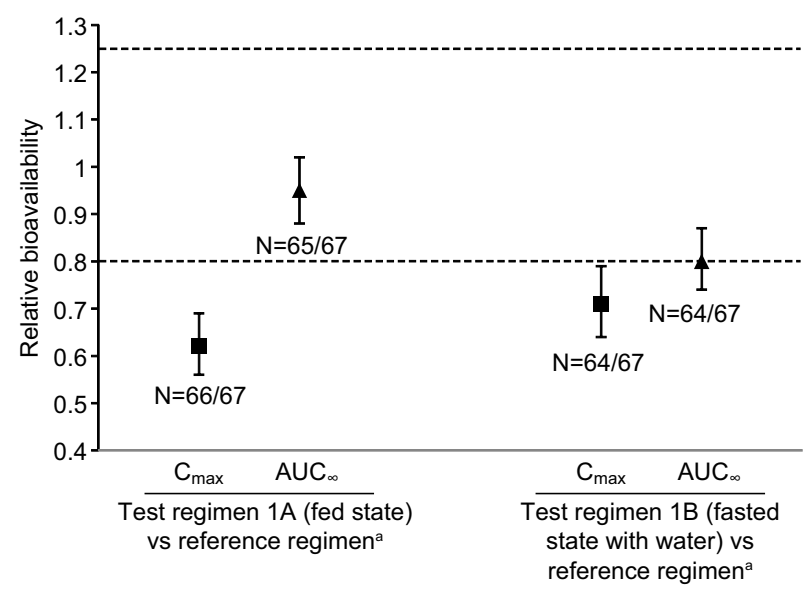

Figure I Study I: statistical comparisons of pharmacokinetic parameter estimates after administration of dexlansoprazole ODT with or without food or water. Notes: $\mathrm{N}$ values are reported as test regimen/reference regimen. Participants with PK parameter data for the reference regimen and one of the test regimens are included in the statistical analyses. Error bars represent $90 \%$ confidence interval;

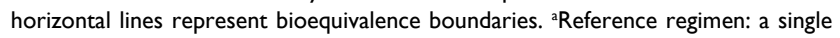
dose of dexlansoprazole $30-\mathrm{mg}$ orally disintegrating tablet was administered on the tongue without water after a minimum 10-hour fast. Participants were instructed to allow the tablet to disintegrate and to swallow the granules without chewing.

Abbreviations: $A \cup C_{\infty}$, area under the plasma concentration-time curve from time 0 to infinity; $C_{\max }$, maximum observed plasma concentration.

\section{Summary of adverse events}

The majority of events in both studies were classified by the investigator as of mild intensity and unrelated to study drug. In study 1 , there was a higher rate of treatment-emergent adverse events among those who received a high-fat meal for breakfast (test regimen $1 \mathrm{~A} ; 21.2 \%$ ) than among those who had fasted (test regimen $1 \mathrm{~B} ; 8.8 \%$ or reference regimen; $13.2 \%$ ). Adverse events that occurred in 2 or more of the study 1 participants with any treatment regimen were headache, arthropod bite, and vessel puncture site pain, occurring at rates of $6.9 \%(n=5)$, $4.2 \%(n=3)$, and $4.2 \%(n=3)$, respectively. Three participants discontinued study 1 because of adverse events, including 1 case of pressured speech and agitation, 1 case of anxietyrelated symptoms, and 1 case of worsening of anemia; all were attributed to preexisting conditions.

In study 2, treatment-emergent adverse events occurred with comparable rates $(6.7 \%-9.3 \%)$, irrespective of the route of administration. Headache $(\mathrm{n}=6 ; 7.8 \%)$ was the only adverse event that occurred in 2 or more study 2 participants with any treatment regimen. Two participants discontinued study 2 because of adverse events, including one participant who was unable to tolerate placement of the NG tube, and one participant who had elevated creatine kinase levels before NG tube regimen dosing at the treatment period 4 check-in visit. The latter participant had creatine kinase levels return to normal after being withdrawn from the study medication. No serious adverse events or deaths were reported in either of the studies.

\section{Discussion}

The studies described were designed to assess the effect of food, water, and alternative routes of administration on the

Table 4 Study 2: pharmacokinetic parameter estimates for dexlansoprazole ODT after using different routes of administration

\begin{tabular}{|c|c|c|c|c|c|c|}
\hline Parameters & $\mathbf{T}_{\max }(\mathbf{h})$ & $C_{\max }(\mathbf{n g} / \mathbf{m L})$ & $A \cup C_{\infty}(n g h / m L)$ & $\mathbf{T}_{1 / 2}(\mathbf{h})$ & CL/F (L/h) & Vz/F (L) \\
\hline \multicolumn{7}{|c|}{ Test regimen 2A: disintegrated in water, administered via oral syringe } \\
\hline Participants (n) & 72 & 72 & 72 & 72 & 72 & 72 \\
\hline Mean \pm SD & NR & $760 \pm 331$ & $3120 \pm 2431.3$ & $1.85 \pm 1.03$ & $13.52 \pm 7.07$ & $32.97 \pm 23.75$ \\
\hline Median (min, max) & $4.00(1.00,6.02)$ & $709(218,1870)$ & $2521(858,17$ 102) & $1.45(0.71,6.13)$ & $11.90(1.75,34.96)$ & $23.57(10.83,120.49)$ \\
\hline$\% \mathrm{CV}$ & NR & 44 & 78 & 56 & 52 & 72 \\
\hline \multicolumn{7}{|c|}{ Test regimen 2B: disintegrated in water, administered via NG tube } \\
\hline Participants (n) & 71 & 71 & 70 & 70 & 70 & 70 \\
\hline Mean \pm SD & NR & $786 \pm 320$ & $3340 \pm 2338.0$ & $1.89 \pm 1.12$ & $12.70 \pm 7.38$ & $31.66 \pm 27.24$ \\
\hline Median (min, max) & $4.00(1.00,12.00)$ & $742(146,1610)$ & $274 \mid(831,13734)$ & I.52 $(0.7 \mathrm{I}, 6.32)$ & $10.95(2.18,36.11)$ & $21.97(11.40,181.30)$ \\
\hline$\% \mathrm{CV}$ & NR & 41 & 70 & 59 & 58 & 86 \\
\hline \multicolumn{7}{|c|}{ Test regimen $2 \mathrm{C}$ : intact tablet swallowed with water } \\
\hline Participants (n) & 74 & 74 & 73 & 73 & 73 & 73 \\
\hline Mean \pm SD & NR & $775 \pm 361$ & $3|2| \pm 2276.4$ & $1.98 \pm 1.19$ & $13.38 \pm 7.30$ & $37.52 \pm 36.64$ \\
\hline Median (min, max) & $4.00(1.50,6.02)$ & $732(116,1810)$ & $2524(8 \mid 4,15454)$ & $1.48(0.71,6.74)$ & II.89 $(1.94,36.84)$ & $22.8 I(I 2.86,237.0 I)$ \\
\hline$\% \mathrm{CV}$ & NR & 47 & 73 & 60 & 55 & 98 \\
\hline \multicolumn{7}{|c|}{ Reference regimen: disintegrated on tongue, swallowed without water } \\
\hline Participants (n) & 74 & 74 & 74 & 74 & 74 & 74 \\
\hline Mean \pm SD & NR & $744 \pm 307$ & $3043 \pm 2087.3$ & $1.86 \pm 0.95$ & $14.02 \pm 8.82$ & $36.13 \pm 34.72$ \\
\hline Median (min, max) & $4.00(1.50,6.03)$ & $703(161,1630)$ & $2414(607,13793)$ & $1.50(0.77,5.02)$ & $12.43(2.17,49.43)$ & $24.35(12.32,208.28)$ \\
\hline$\% \mathrm{CV}$ & NR & 41 & 69 & 51 & 63 & 96 \\
\hline
\end{tabular}

Notes: Because of variability in the terminal phase of the plasma concentration-time curve, the terminal elimination rate constant could not be determined for some study participants, and therefore the PK parameters that use this constant in their calculations (i.e., $\mathrm{T}_{1 / 2}, \mathrm{AUC} \mathrm{C}_{\infty}, \mathrm{CL} / \mathrm{F}$, and $\mathrm{Vz} / \mathrm{F}$ ) could not be estimated.

Abbreviations: $\mathrm{AUC}_{\infty}$, area under the plasma concentration-time curve from time 0 to infinity; $\mathrm{CL} / \mathrm{F}$, apparent clearance after extravascular administration; $\mathrm{C}_{\text {max }}$, maximum observed plasma concentration; \%CV, percent coefficient of variation; max, maximum; min, minimum; NG, nasogastric; NR, not reported; ODT, orally disintegrating tablet; PK, pharmacokinetic; SD, standard deviation; $T_{1 / 2}$, terminal elimination half-life; $T_{\text {max }}$, time to reach maximum observed plasma concentration; $V z / F$, apparent volume of distribution after extravascular administration. 
Table 5 Study 2: statistical comparisons of pharmacokinetic parameter estimates for dexlansoprazole ODT after using different routes of administration

\begin{tabular}{|c|c|c|c|}
\hline \multirow[t]{2}{*}{ Parameters } & \multicolumn{2}{|c|}{ Participants (n) } & \multirow{2}{*}{$\begin{array}{l}\text { Relative bioavailability } \\
\text { point estimate }(90 \% \mathrm{Cl})\end{array}$} \\
\hline & Test & Reference & \\
\hline \multicolumn{4}{|c|}{ Test regimen $2 \mathrm{~A}$ (disintegrated in water via oral syringe) } \\
\hline \multicolumn{4}{|c|}{ vs reference regimen ${ }^{a}$} \\
\hline $\mathrm{C}_{\max }$ & 72 & 74 & $1.0218(0.9318-1.1205)$ \\
\hline AUC $_{\infty}$ & 72 & 74 & $1.0070(0.94 \mathrm{II}-1.0776)$ \\
\hline \multirow{2}{*}{\multicolumn{4}{|c|}{ Test regimen 2B (disintegrated in water via NG tube) vs }} \\
\hline & & & \\
\hline $\mathrm{C}_{\max }$ & 71 & 74 & $1.0613(0.9674-1.1644)$ \\
\hline $\mathrm{AUC}_{\infty}$ & 70 & 74 & $1.0814(1.0100-1.1579)$ \\
\hline \multicolumn{4}{|c|}{$\begin{array}{l}\text { Test regimen } 2 C \text { (intact tablet swallowed with water) vs } \\
\text { reference regimen }\end{array}$} \\
\hline $\mathrm{C}_{\max }$ & 74 & 74 & $1.0040(0.9164-1.1000)$ \\
\hline$A U C_{\infty}$ & 73 & 74 & $1.0191(0.9527-1.0901)$ \\
\hline
\end{tabular}

Notes: Participants with PK parameter data for the reference regimen and one of the test regimens are included in the statistical analyses. ${ }^{\text {Reference regimen: a }}$ single dose of dexlansoprazole 30-mg ODT was administered on the tongue without water after a $\geq 10$-hour fast. Participants were instructed to allow the tablet to disintegrate and to swallow the granules without chewing

Abbreviations: $\mathrm{AUC}_{\infty}$, area under the plasma concentration-time curve from time 0 to infinity; $\mathrm{Cl}$, confidence interval; $\mathrm{C}_{\max }$, maximum observed plasma concentration; NG, nasogastric; ODT, orally disintegrating tablet; PK, pharmacokinetic.

pharmacokinetic parameters of dexlansoprazole derived from the novel 30-mg ODT formulation. Approved in 2009, the dual delayed-release dexlansoprazole capsule formulation has proven efficacy ${ }^{3,8}$; however, swallowing the capsule whole may prove difficult for some patients.
In general, patients who have difficulty in swallowing have been found to be less compliant. ${ }^{24}$ Other options for patients who have trouble in swallowing dexlansoprazole capsules include opening the capsule and administering the granules mixed with water in an oral syringe, via a size 16 French or larger NG tube, or by sprinkling the granules on applesauce. ${ }^{3,25}$ However, greater adherence has been reported with ODT administration, and dysphagic patients have reported a preference for ODT delivery. ${ }^{24,26}$ Dexlansoprazole ODT, which is formulated to disintegrate in the mouth without water when placed on the tongue, provides dosing flexibility for these patients.

Hospitalized patients may require a NG tube for severe dysphagia and for traumatic medical events, severe malnutrition, or a range of neurologic disorders. ${ }^{17}$ Oral syringes are the preferred apparatus for dispensing oral liquid medications in inpatient settings. ${ }^{27}$ The microgranules contained in the dexlansoprazole ODT are smaller than the granules in the capsule formulation and therefore much easier to disperse in water and administer in an oral syringe or a smaller NG tube (e.g., size 8 French). The results reported here demonstrate that similar systemic exposure to dexlansoprazole was achieved when swallowed intact with water or disintegrated in water and administered orally via a syringe or directly to the stomach via NG tube vs the ODT being swallowed without water after disintegration on the tongue. Bioequivalence

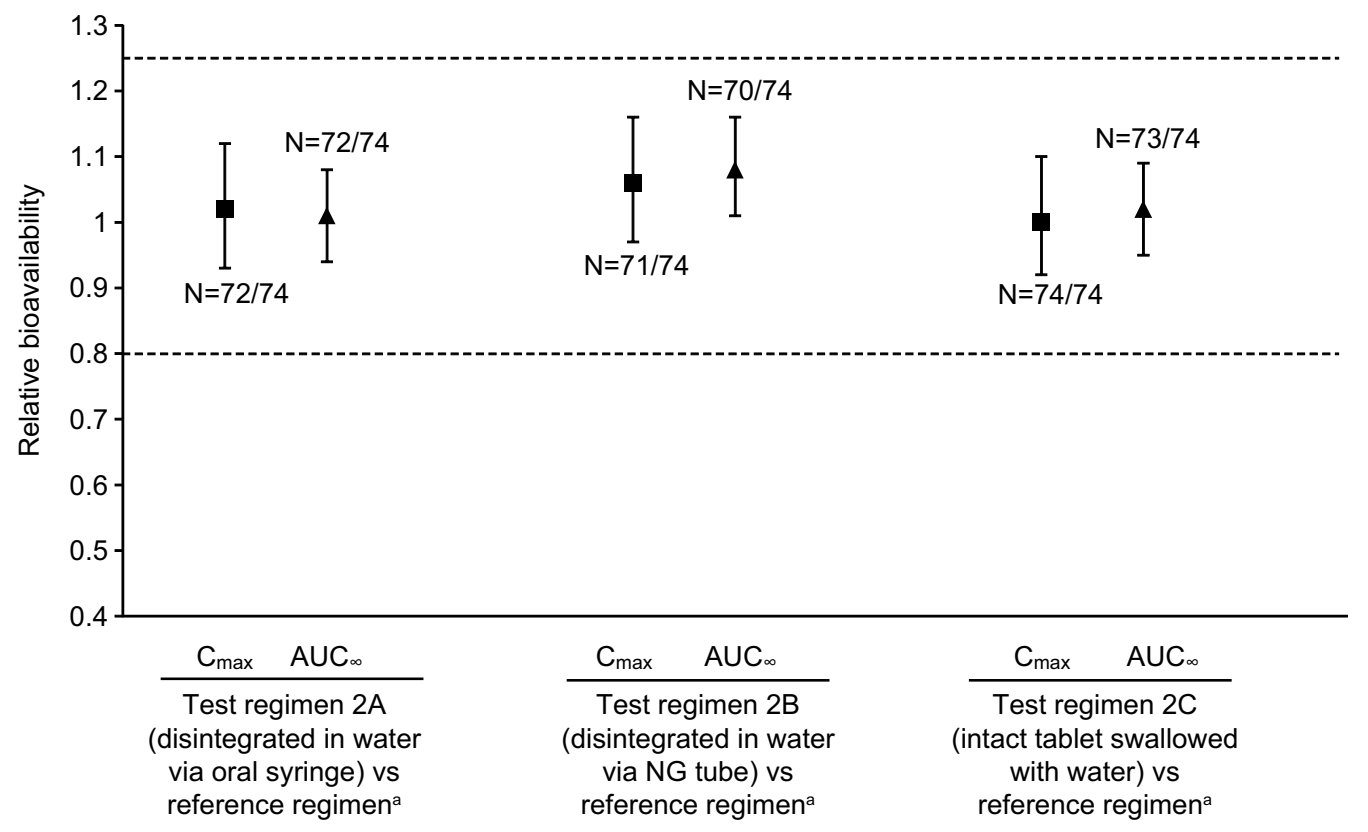

Figure 2 Study 2: statistical comparisons of pharmacokinetic parameter estimates for dexlansoprazole ODT after using different routes of administration.

Notes: $\mathrm{N}$ values are reported as test regimen/reference regimen. Participants with PK parameter data for the reference regimen and one of the test regimens are included in the statistical analyses. Error bars represent $90 \%$ confidence interval; horizontal lines represent bioequivalence boundaries. ${ }^{a}$ Reference regimen: a single dose of dexlansoprazole 30-mg ODT was administered on the tongue without water after a minimum 10-hour fast. Participants were instructed to allow the tablet to disintegrate and to swallow the granules without chewing.

Abbreviations: $A \cup C_{\infty}$, area under the plasma concentration-time curve from time 0 to infinity; $C_{\max }$, maximum observed plasma concentration; ODT, orally disintegrating tablet; PK, pharmacokinetic. 
between the alternative routes of administration evaluated suggests that the dispersal of ODT in water can be a suitable alternative for patients unable to receive oral therapy.

Compared with the consistent bioavailability observed for the dexlansoprazole ODT after using the different routes of administration in study 2 (including the administration of an intact ODT with water), a moderate decrease in dexlansoprazole bioavailability was observed when dexlansoprazole ODT was placed on the tongue, allowed to disintegrate, swallowed, and then followed with a $240-\mathrm{mL}$ water rinse in study 1 . These unexpected results are somewhat contradictory, and the cause of the decrease in bioavailability when a water rinse is used after standard ODT administration is not readily apparent. The difference in $\mathrm{C}_{\max }$ with the water rinse is not considered to negatively affect the overall pharmacodynamic profiles of the ODT formulation, because previous studies have confirmed that the pharmacodynamic effect (increase in intragastric $\mathrm{pH}$ ) of PPIs is associated with AUC and not $\mathrm{C}_{\max }{ }^{28-30}$ In one of these studies, Vakily et al performed pharmacokinetic/pharmacodynamic modeling of the exposure-response relationship between dexlansoprazole AUC and the percent of time $\mathrm{pH}>4$ over a 24-hour period following multiple doses of the dexlansoprazole capsule. ${ }^{30}$ The relationship between pharmacologic response and dexlansoprazole AUC was described using a simple maximum effect $\left(\mathrm{E}_{\max }\right)$ model: $\mathrm{E}=\mathrm{E}_{\max } \times \mathrm{AUC}_{\mathrm{t}} / \mathrm{EC}_{50}+\mathrm{AUC}_{\mathrm{t}}$, where $\mathrm{E}$ is the predicted pharmacologic response, $\mathrm{E}_{\text {max }}$ is the maximum predicted pharmacologic response, and $\mathrm{EC}_{50}$ is the $\mathrm{AUC}_{\mathrm{t}}$ (AUC from time 0 to the last measurable concentration) that produces $50 \%$ of the $\mathrm{E}_{\max }$. Using this model and a dexlansoprazole $\mathrm{E}_{\max }$ of $71 \%$ and dexlansoprazole $\mathrm{EC}_{50}$ on day 5 of $642 \mathrm{ng} \cdot \mathrm{h} / \mathrm{mL}$, as reported by Vakily et al for the percent of time $\mathrm{pH}>4$, we assessed the effect of the decreased AUC on overall $\mathrm{pH}$ control. ${ }^{30}$ The mean $\mathrm{AUC}_{\mathrm{t}}$ for the $30-\mathrm{mg}$ ODT administered on the tongue without water followed by a water rinse $(2351 \mathrm{ng} \cdot \mathrm{h} / \mathrm{mL})$ would be predicted to result in a $\mathrm{pH}>4$ for $55.8 \%$ of a 24 -hour period, whereas the mean $\mathrm{AUC}_{t}$ for the 30-mg ODT administered on the tongue without water (2789 $\mathrm{ng} \cdot \mathrm{h} / \mathrm{mL}$ ) would result in a $\mathrm{pH}>4$ for $57.7 \%$ of the time. The predicted $1.9 \%$ decrease in the percent of time $\mathrm{pH}$ $>4$ is not expected to have a substantial effect on the ability of dexlansoprazole to increase intragastric $\mathrm{pH}$, despite a $20 \%$ decrease in AUC when the ODT was administered with a water rinse.

The $90 \%$ CIs for the central value ratios of dexlansoprazole AUC between the ODT administered in the fed condition relative to the fasted state were contained within the bioequivalence range of $0.80-1.25$. However, administration of the ODT with food resulted in a 38\% reduction in dexlansoprazole $\mathrm{C}_{\max }$. Literature suggests that the antisecretory effect of PPIs is generally acknowledged to be proportional to the AUC, ${ }^{28,29}$ and in light of these studies, the demonstrated pharmacokinetic equivalence of the AUC values achieved with the ODT administered with or without food suggests that the pharmacodynamic response would be similar following administration of the $30 \mathrm{mg}$ ODT in the fed condition or in the fasted state. The reduced $\mathrm{C}_{\max }$ in the fed condition may not be expected to affect the efficacy or safety profiles of dexlansoprazole ODT. However, due to the reduced $\mathrm{C}_{\max }$ value observed in the fed state, the prescribing information for the dexlansoprazole 30-mg ODT indicates that it should be administered at least 30 minutes before a meal. ${ }^{3}$

The dexlansoprazole capsule has been available for many years as a safe and effective treatment option for patients with heartburn, GERD, or EE but options for patients with difficulty swallowing were limited to the administration via oral syringe, NG tube, or applesauce. The dual delayed-release of 30-mg dexlansoprazole ODT formulation offers advantages in convenience and compliance for patients with swallowing difficulty. Both dexlansoprazole ODT and capsule are approved in 30-mg doses for the treatment of heartburn in symptomatic nonerosive GERD and for the maintenance of healed EE and relief of heartburn. ${ }^{3}$ Dexlansoprazole ODT is a promising treatment option for patients $\geq 12$ years of age seeking the efficacy of the dual delayed-release of $30-\mathrm{mg}$ dexlansoprazole capsule with the flexibility in dosing options that the ODT provides.

\section{Acknowledgments}

Medical writing assistance was provided by Nafis Islam, PharmD, and Bomina Yu, PhD, CMPP, of inVentiv Medical Communications, which was supported by Takeda Pharmaceuticals USA, Inc. The authors thank both Dr. Michael Cwik, an employee of Takeda and the staff of PPD, Middleton, WI, for conducting the bioanalytical portion of the study. The authors also thank Ms. Angela Gamble and Ms. Kelly Hanna for managing the conduct of studies 1 and 2, respectively.

All authors had access to the data and vouch for the veracity and completeness of the data and the data analysis. Funding for this study was provided by Takeda Development Center Americas, Inc.

\section{Author contributions}

All authors contributed toward data analysis, drafting and revising the paper and agree to be accountable for all aspects of the work. 


\section{Disclosure}

All authors are employees of Takeda Development Center Americas, Inc., a wholly owned subsidiary of Takeda Pharmaceuticals America, Inc. The authors report no other conflicts of interest in this work.

\section{References}

1. Katz PO, Gerson LB, Vela MF. Guidelines for the diagnosis and management of gastroesophageal reflux disease. Am J Gastroenterol. 2013;108(3):308-328; quiz 329.

2. Dent J, El-Serag HB, Wallander MA, Johansson S. Epidemiology of gastro-oesophageal reflux disease: a systematic review. Gut. 2005;54(5): 710-717.

3. Dexilant and Dexilant SoluTab [package insert] Deerfield, IL: Takeda Pharmaceuticals America Inc.,; 2016.

4. Sharma P, Shaheen NJ, Perez MC, et al. Clinical trials: healing of erosive oesophagitis with dexlansoprazole MR, a proton pump inhibitor with a novel dual delayed-release formulation - results from two randomized controlled studies. Aliment Pharmacol Ther. 2009;29(7):731-741.

5. Metz DC, Howden CW, Perez MC, Larsen L, O’Neil J, Atkinson SN. Clinical trial: dexlansoprazole MR, a proton pump inhibitor with dual delayed-release technology, effectively controls symptoms and prevents relapse in patients with healed erosive oesophagitis. Aliment Pharmacol Ther. 2009;29(7):742-754.

6. Peura DA, Metz DC, Dabholkar AH, Paris MM, Yu P, Atkinson SN. Safety profile of dexlansoprazole MR, a proton pump inhibitor with a novel dual delayed release formulation: global clinical trial experience. Aliment Pharmacol Ther. 2009;30(10):1010-1021.

7. Dabholkar AH, Han C, Paris MM, Perez MC, Atkinson SN, Peura DA. The 12-month safety profile of dexlansoprazole, a proton pump inhibitor with a dual delayed release formulation, in patients with gastrooesophageal reflux disease. Aliment Pharmacol Ther. 2011;33(3): 366-377.

8. Lee RD, Vakily M, Mulford D, Wu J, Atkinson SN. Clinical trial: the effect and timing of food on the pharmacokinetics and pharmacodynamics of dexlansoprazole MR, a novel Dual Delayed Release formulation of a proton pump inhibitor - evidence for dosing flexibility. Aliment Pharmacol Ther. 2009;29(8):824-833.

9. Sonies BC, Dalakas MC. Dysphagia in patients with the post-polio syndrome. N Engl J Med. 1991;324(17):1162-1167.

10. Daniels SK. Neurological disorders affecting oral, pharyngeal swallowing. GI Motility Online. 2006. http://www.nature.com/gimo/contents/ pt1/full/gimo34.html. Accessed January 1, 2017.

11. Jaradeh S. Muscle disorders affecting oral and pharyngeal swallowing. GI Motility Online. 2006. http://www.nature.com/gimo/contents/pt1/ full/gimo35.html. Accessed January 1, 2017.

12. Sheehan NJ. Dysphagia and other manifestations of oesophageal involvement in the musculoskeletal diseases. Rheumatology (Oxford). 2008;47(6):746-752.

13. Yan BM, Shaffer EA. Eosinophilic esophagitis: a newly established cause of dysphagia. World J Gastroenterol. 2006;12(15):2328-2334.

14. Maeda T, Nagata K, Satoh Y, Yamazaki T, Takano D. High prevalence of gastroesophageal reflux disease in Parkinson's disease: a questionnairebased study. Parkinsons Dis. 2013;2013:742128.
15. Locke GR 3rd, Talley NJ, Fett SL, Zinsmeister AR, Melton LJ 3rd. Prevalence and clinical spectrum of gastroesophageal reflux: a population-based study in Olmsted County, Minnesota. Gastroenterology. 1997;112(5):1448-1456.

16. Cho SY, Choung RS, Saito YA, et al. Prevalence and risk factors for dysphagia: a USA community study. Neurogastroenterol Motil. 2015;27(2):212-219.

17. Ciocon JO. Indications for tube feedings in elderly patients. Dysphagia. 1990; 5 (1):1-5.

18. Kukulka M, Nudurupati S, Perez MC. Pharmacokinetics and pharmacodynamics of an orally disintegrating tablet formulation of dexlansoprazole. Therap Adv Gastroenterol. 2016;9(6):759-769.

19. Food and Drug Administration Center for Drug Evaluation and Research (CDER), US Department of Health and Human Services. Guidance for Industry: Bioavailability and Bioequivalence Studies Submitted in NDAs or INDs-General Considerations. Rockville, MD: Food and Drug Administration; March 2014. Available from: http://www. fda.gov/downloads/drugs/guidancecomplianceregulatoryinformation/ guidances/ucm389370.pdf. Accessed January 1, 2017.

20. Food and Drug Administration Center for Drug Evaluation and Research (CDER), US Department of Health and Human Services. Guidance for Industry: Food-Effect Bioavailability and Fed Bioequivalence Studies. Rockville, MD: Food and Drug Administration; December 2002. Available from: http://www.fda.gov/downloads/RegulatoryInformation/ Guidances/UCM126833.pdf. Accessed January 1, 2017.

21. World Medical Association. World Medical Association Declaration of Helsinki: ethical principles for medical research involving human subjects. JAMA. 2013;310(20):2191-2194.

22. International Conference on Harmonisation of technical requirements for registration of pharmaceuticals for human $\mathrm{u}$. ICH harmonized tripartite guideline: guideline for Good Clinical Practice. J Postgrad Med. 2001;47(1):45-50.

23. FDAAA 801 Requirements ClinicalTrials.gov website. [Updated November 2015]. Available from: https://clinicaltrials.gov/ct2/managerecs/fdaaa. Accessed June 22, 2016.

24. Carnaby-Mann G, Crary M. Pill swallowing by adults with dysphagia. Arch Otolaryngol Head Neck Surg. 2005;131(11):970-975.

25. Czerniak R, Vakily, M, Wu, J. TAK-390MR, a novel dual delayed release formulation of a PPI, is bioequivalent when administered as granules sprinkled over applesauce or as an intact capsule. Am J Gastroenterol. 2008;103:S4-S5. Abstract 12

26. Maalouf N. Developing patient-centric drug formulations to meet patient needs. Business Dev Licensing J. 2013;(20):1-4.

27. Grissinger M. Oral syringes: making better use of a crucial and economical risk-reduction strategy. P T. 2013;38(1):5-6.

28. Hunt RH, Armstrong D, James $\mathrm{C}$, et al. Effect on intragastric $\mathrm{pH}$ of a PPI with a prolonged plasma half-life: comparison between tenatoprazole and esomeprazole on the duration of acid suppression in healthy male volunteers. Am J Gastroenterol. 2005;100(9):1949-1956.

29. Lind T, Rydberg L, Kyleback A, et al. Esomeprazole provides improved acid control vs. omeprazole in patients with symptoms of gastro-oesophageal reflux disease. Aliment Pharmacol Ther. 2000;14(7):861-867.

30. Vakily M, Zhang W, Wu J, Atkinson SN, Mulford D. Pharmacokinetics and pharmacodynamics of a known active PPI with a novel Dual Delayed Release technology, dexlansoprazole MR: a combined analysis of randomized controlled clinical trials. Curr Med Res Opin. 2009;25(3):627-638. 


\section{Supplementary materials}

Table SI Study I treatment sequences

\begin{tabular}{lllllll}
\hline Sequence & Participants (n) & & & \multicolumn{2}{l}{ Treatment regimen } & \\
\cline { 2 - 3 } \cline { 5 - 7 } & Planned & Enrolled & & Period I & Period 2 & Period 3 \\
\hline I & 24 & 24 & Test IB & Reference \\
2 & 24 & 24 & Test IB & Reference & Test IA \\
3 & 24 & 24 & Reference & Test IA & Test IB \\
\hline
\end{tabular}

Notes: Test IA: a single dose of dexlansoprazole 30-mg ODT administered on the tongue without water, 30 minutes after a high-fat meal. Test IB: a single dose of dexlansoprazole 30-mg ODT administered on the tongue without water after a $\geq 10$-hour fast, followed with a 240-mL water rinse. Reference: a single dose of dexlansoprazole 30-mg ODT administered on the tongue without water after a $\geq 10$-hour fast. Participants were instructed to allow the tablet to disintegrate and to swallow the granules without chewing

Abbreviation: ODT, orally disintegrating tablet.

Table S2 Study 2 treatment sequences

\begin{tabular}{|c|c|c|c|c|c|c|}
\hline \multirow[t]{2}{*}{ Sequence } & \multicolumn{2}{|c|}{ Participants (n) } & \multicolumn{4}{|c|}{ Treatment regimen } \\
\hline & Planned & Enrolled & Period I & Period 2 & Period 3 & Period 4 \\
\hline I & 20 & 18 & Test 2A & Test 2B & Reference & Test $2 \mathrm{C}$ \\
\hline 2 & 20 & 19 & Test $2 B$ & Test $2 \mathrm{C}$ & Test $2 \mathrm{~A}$ & Reference \\
\hline 3 & 20 & 20 & Test 2C & Reference & Test 2B & Test $2 \mathrm{~A}$ \\
\hline 4 & 20 & 20 & Reference & Test 2A & Test 2C & Test 2B \\
\hline
\end{tabular}

Notes: Test 2A: a single dose of dexlansoprazole 30-mg ODT disintegrated in water and administered via oral syringe. Test 2B: a single oral dose of dexlansoprazole 30$\mathrm{mg}$ ODT disintegrated in water and administered via NG tube. Test 2C: a single oral dose of dexlansoprazole 30-mg ODT swallowed intact with water. Reference: a single dose of dexlansoprazole 30-mg ODT administered on the tongue without water after a 10-hour fast. Participants were instructed to allow the tablet to disintegrate and to swallow the granules without chewing.

Abbreviations: NG, nasogastric; ODT, orally disintegrating tablet.

Clinical and Experimental Gastroenterology

\section{Publish your work in this journal}

Clinical and Experimental Gastroenterology is an international, peerreviewed, open access, online journal publishing original research, reports, editorials, reviews and commentaries on all aspects of gastroenterology in the clinic and laboratory. This journal is included on PubMed. The manuscript management system is completely online

\section{Dovepress}

and includes a very quick and fair peer-review system, which is all easy to use. Visit http://www.dovepress.com/testimonials.php to read real quotes from published authors. 